\title{
INTERDISCIPLINARIDADE E ENSINO DE LÍNGUAS
}

Sara Regina Scotta Cabral

\section{RESUMO}

As ciências humanas cada vez se tornam mais especializadas, devido ao processo de complexificação por que passam as sociedades humanas. Não se pode ignorar o novo paradigma que ora se apresenta - o da ordem aliada à desordem e à organização. É no trabalho com línguas, especialmente no ensino de línguas estrangeiras, que cada vez mais se observa a presença do diferente étnica, social e politicamente. Trabalhar em uma perspectiva intercultural pode ser a solução (Morin, 2000; Fleuri, 2003), de modo que uma orientação pragmática do uso da linguagem permita aos sujeitos envolvidos no processo um movimento dialógico-discursivo, em que a interpretação dos fatos culturais articule-se com a culturalidade.

\section{EDUCAÇÃO E INTERDISCIPLINARIDADE}

Não há dúvida de que o mundo atual em nada se parece com o das eras anteriores. No decorrer de sua história, o homem passou por vários estágios de desenvolvimento e, conseqüentemente, de formas de educação. Das escolas gregas até as escolas do século XXI, várias orientações didático-pedagógicas se configuraram, cada qual de acordo com os postulados filosóficos da respectiva época.

Hoje, com as relações transnacionais que se evidenciam nos campos político e econômico e também com o advento da internet, diferentes pessoas e diferentes grupos podem interagir de múltiplos lugares em sistemas de rede on-line. O resultado é a crescente miscigenação cultural, étnica e, por que não dizer, biológica. É cada vez mais comum ter-se grupos de profissionais, amigos, alunos ou colegas advindos das mais longínquas partes do mundo.

Fazendo-se um recorte desse cenário e enfocando a realidade brasileira, os Parâmetros Curriculares Nacionais (PCNs) para a educação fundamental, em 1997, já elegiam a pluralidade cultural como um dos temas transversais. Sabe-se que o Brasil, por sua história peculiar, é um povo miscigenado, em que mais facilmente se aceita a mistura cultural e étnica proveniente da convivência entre portugueses, índios e negros.

Entretanto, alguns poucos movimentos foram organizados a fim de se pensar a cultura popular: os Centros Populares de Cultura, o Movimento de Educação de 
Base, o Movimento da Cultura Popular, a proposta de Paulo Freire e os movimentos de base, como associação de moradores, comunidades eclesiais e movimentos sindicais (Fleuri, 2003a).

No Brasil avultam os movimentos em busca das identidades, iniciativas oriundas de grupos ditos excluídos, como negros, mulheres, homossexuais, crianças trabalhadoras, etc. Cria-se então a necessidade de uma educação intercultural, em que "a complexidade das relações sociais e interculturais do mundo contemporâneo requer novas formas de se elaborar o conhecimento no campo da pesquisa e da educação" (idem). Um dos maiores desafios que os educadores enfrentam hoje é saber como transitar em vários grupos e como trabalhar em sala de aula com a diversidade, cada vez mais evidente.

Há que se fazer uma diferenciação. Em uma sociedade monocultural, todos compartilham de uma mesma cultura, ou seja, os grupos minoritários curvam-se aos padrões dominantes e aderem ao modelo vigente. Já as sociedades multiculturais ou pluriculturais apresentam grupos diversos em que se "reconhece que cada cultura é válida em si mesma, na medida em que corresponde às necessidades e às opções de uma coletividade" (idem). São grupos diferentes que coexistem sem necessariamente interagir com o outro. Tal situação "pode justificar a fragmentação ou a criação de guetos culturais, que reproduzem desigualdades e discriminações sociais" (idem).

Numa perspectiva mais ampla, apresenta-se a sociedade intercultural, em que pessoas de culturas diferentes interagem, intencionalmente, e não apenas mantêm atitude de tolerância umas com as outras. Conseqüência de tais visões de cultura reflete-se diretamente na prática educativa. Segundo Fleuri (2003a), na

\begin{abstract}
perspectiva multicultural, entende-se, de modo geral, as culturas diferentes como objetos de estudo, como matéria a ser aprendida. Ao contrário, na perspectiva intercultural os educadores e educandos não reduzem a outra cultura a um objeto de estudo a mais, mas a consideram como um modo próprio de um grupo social ver e interagir com a realidade.
\end{abstract}

Na ótica do intercultural, a ênfase é dada aos sujeitos: não são culturas diferentes que se defrontam, mas sujeitos diferentes que, além de coexistirem, transitam cognitivamente outros saberes e experiências. Nesse viés, a educação passa a ser concebida como "construção de processos em que diferentes sujeitos desenvolvem 
relações de reciprocidade (cognitiva e conflitual) entre si" (idem). Emerge, nesse caso, a questão da complexidade (Morin, 2000, p. 55-60), em que dificuldades e incerteza coexistem, mais do que clareza e resposta. Em todas as áreas da ciência, sejam humanas ou exatas, trabalha-se com o plural, o contrário, o complicado, o desordenado. Tal panorama reside, fundamentalmente, nas diversas visões dos atores envolvidos em sociedades multiculturais.

Para Morin (idem), faz-se necessária uma mudança de epistemologia, em que se passe das relações opositivas disjuntivas (ou/ou) para relações interativas e emancipatórias (e/e) no modo de entender o mundo. Ou seja, há a necessidade de uma dialogia entre os sujeitos, em que "duas lógicas, duas 'naturezas', dois princípios são coligados em uma unidade sem que com isto a dualidade se dissolva na unidade" (Morin, 1985, p. 57).

É nesse contexto, na busca de uma educação que tenha como ponto de partida a complexidade das sociedades modernas, especialmente a brasileira, que se vê a necessidade de um ensino a serviço da interdisciplinaridade. $O$ ensino de línguas, quer materna quer estrangeiras, pode ser um terreno fértil para a real interação entre os diversos grupos étnicos e sociais.

\section{COMPLEXIDADE E ENSINO DE LÍNGUAS}

Quando o professor se propuser a trabalhar em uma perspectiva de educação intercultural, é preciso que redimensione seu modo de compreender a realidade, bem como suas práticas educativas. Trabalhar em contextos complexos, múltiplos, diferenciados, colocando-se como sujeito da ação educativa junto aos outros sujeitos que são os alunos, exige mudanças profundas, tais como a concepção do lugar de onde fala e com quem fala. Trazer o aluno à condição de ator de seu próprio processo não é tarefa fácil. Para Fleuri (2003b), tal mudança só se efetivará se se reconhecer a concepção de Bateson quanto à pesquisa antropológica, vista "não mais como um processo de conhecimento objetivo de outras culturas, mas como o estabelecimento de um contexto relacional novo entre sujeitos de contextos socioculturais diferentes" (Feuri, 1999). No bem dizer de Bateson (apud Fleuri, 2003b), deseja-se um ensino assentado na "ecologia da mente". 
Particularmente, o trabalho com línguas presta-se, nos três graus de ensino, aos propósitos de uma concepção intercultural, em que se possa convergir para o "estudo da condição humana" (Morin, 2000, p. 43). Sabe-se que homem, língua e cultura se interrelacionam e estão de tal modo entrelaçados que um não se faz senão em presença do outro.

Morin (2000, p. 75-85) explicita as finalidades do ensino para os três graus (primário, secundário e universitário). No primário, sugere um programa interrogativo, através do qual seriam promovidas descobertas das "dimensões psicológicas, sociais, históricas da realidade humana. A partir da aventura da hominização (...) seria colocado o problema do surgimento do Homo Sapiens, da cultura, da linguagem, do pensamento..." (Morin, 2000, p. 76). Seria na escola primária que o aluno começaria a perceber que o homem, além de biológico, é um ser totalmente cultural e que "o surgimento da mente supõe a linguagem e a cultura" (idem, ibidem). O estudo de gêneros da mídia, da TV, das agências publicitárias mostra algumas formas de expressão da cultura e, por conseguinte, das ideologias subjacentes a eles. O papel do professor, nesse caso, não seria o de denunciar, mas o de "tornar conhecidos os modos de produção dessa cultura" (idem, p. 78), através de comentários sobre os programas e/ou jogos vistos e/ou praticados pelos alunos, mesmo fora da sala de aula. Ao mesmo tempo, Morin (idem, p. 78) sugere também o ensino de língua, ortografia, história e cálculo, ao longo de todo o ensino primário.

Já no ensino secundário, estabelecer-se-ia o diálogo entre as diversas culturas das humanidades e das ciências, em que a literatura exerceria papel de destaque. $O$ professor, nesse grau de ensino, deveria também abrir-se às diversas manifestações da mídia e não ignorá-las, pois um ensino que pretenda trabalhar a condição humana não pode desvincular seu aluno do contexto em que ele está inserido. O conhecimento da cultura midiática faz-se necessária não só para "compreender os processos multiformes de industrialização e supercomercialização culturais, mas também o quanto das aspirações e obsessões próprias a nosso "espírito da época" é traduzido e traído pela temática das mídias" (Morin, 2000, p. 80).

No terceiro grau, a universidade deveria constituir espaço de problematização, cuja missão é transecular e transnacional. Ao conceber uma Faculdade do Cosmo e uma Faculdade da Terra, Morin também prevê a preservação das Faculdades de Letras, "acompanhada de uma revitalização de seu ensino (...) e de uma abertura às 
artes, bem como ao cinema". Ao propor um "dízimo epistemológico ou transdisciplinar" referente a um ensino comum a todas as disciplinas, $10 \%$ de duração dos cursos seriam dirigidos para, entre outros temas, a interpretação, a argumentação e a literatura.

A literatura é enfatizada por Morin (2000, p. 91), uma vez que esconde, sob a aparência da simplicidade, toda a complexidade humana com suas tragédias e seus romances, em que pontilham passagens de ódio, amor, doença, morte, felicidade, drogas, traição, dinheiro e outros. "Todas as obras-primas da literaturas foram obrasprimas de complexidade: a revelação da condição humana na singularidade do indivíduo (Montaigne), a contaminação do real pelo imaginário (o Dom Quixote, de Cervantes), o jogo das paixões humanas (Shakespeare)" (Morin, 2000, p. 91). O autor alerta também para o papel que a metáfora exerce nos contextos literários, a qual fornece "precisões que a língua puramente objetiva ou denotativa não pode fornecer" (idem, p. 92).

\section{INTERDISCIPLINARIDADE E ENSINO DE LÍNGUAS}

Morin (2000, p. 105) conceitua disciplina como "uma categoria organizadora dentro do conhecimento científico" a qual institui a divisão e a especialização do trabalho, sendo diversas como as áreas das ciências humanas, biológicas e exatas. Conforme o mesmo autor (idem, p. 105), "uma disciplina tende naturalmente à autonomia pela delimitação de fronteiras, da linguagem, em que ela se constitui, das técnicas que é levada a elaborar e a utilizar e, eventualmente, pelas teorais que lhe são próprias."

Toda disciplina destaca ou constrói um objeto de estudo não trivial. Entretanto, na medida em que se hiperespecializa, corre, segundo Morin (2000, p. 106), o perigo da coisificação do objeto estudado, em que tal se torna auto-suficiente e apaga os elos de solidariedade com as outras disciplinas. Entretanto, como tudo no mundo pertence a sistemas, torna-se bastante perigoso isolar os objetos para estudá-los apartados da realidade em que estão inseridos. É preciso 'abrir' a disciplina para suas relações com o mundo e trabalhar em uma perspectica inter-poli-transdisciplinar, de modo a impedir que os conceitos se esvaziem e provoquem seu fechamento. Ademais, sabe-se da abertura às interferências de algumas disciplinas em outras (ex. 
revolução biológica dos anos 50, biologia molecular e outras) que sofreram interferência da física. Outro exemplo é a disciplina de história, que se presta a uma configuração multifocalizadora e multidimensional, para a qual convergem várias outras disciplinas. Seja pela circulação de conceitos, seja pela conplexificação das disciplinas ou pela emergência de novos esquemas cognitivos, é importante que as disciplinas, mesmo conservando seu campo de visão, percebam as ligações e a solidariedade entre elas.

O grande problema, pois, é encontrar a difícil via de interarticulação entre as ciências que têm, cada uma delas, não apenas sua linguagem própria, mas também conceitos fundamentais que não podem ser transferidos de uma linguagem a outra (Morin, 2000, p.114). O paradigma que se impõe é, então, o da ordem aliada à desordem e à organização, em que a desordem, ao invés de ser afastada, é estudada em conjunto com o todo. A forma e o fundo organizam o universo e as disciplinas diferentes entre si. Em decorrência, ressurgem os conceitos de intertransdisciplinaridade que, segundo Morin (2000, p. 115), podem atravessar as diferentes disciplinas, já que "são os complexos de inter-multi-transdisciplinaridade que realizaram e desempenharam um fecundo papel na história das ciências" (idem). É do projeto comum que nasce a ecologização das disciplinas, que leva em conta tudo que lhes é contextual.

Nesse cenário, avulta a importância dos sujeitos envolvidos no processo educacional (alunos e professores): se o Eu só se constrói em vista do Outro ("eu sou um outro em mim mesmo" - Sartre, apud Abdallah-Pretceille e Porcher, 1996, p. 57), é errôneo afirmar que o intercultural é unicamente um fenômeno sociológico ou mesmo antropológico. A cultura é vivida pelo sujeito que a porta e que é atravessado por ela. Então, a abordagem intercultural é uma abordagem intersubjetiva, o que equivale a dizer que o processo de troca entre as culturas perfaz o mesmo caminho.

Abdallah-Preitcelle e Porcher (1996, p. 58) afirmam que as conseqüências pedagógicas da "fenomenologia intercultural" são consideráveis, em que emerge a discussão sobre o diferente. Para os mesmos autores (p. 59), a educação intercultural é "uma das modalidades possíveis de tratamento da diversidade cultural na escola, de todas as formas de diversidade (...), vinculada especialmente à aprendizagem das línguas estrangeiras" (idem). 
Afirmam ainda os autores que a cultura não existe fora de uma formulação discursiva. Ela não é o reflexo de uma realidade objetiva, mas o resultado de uma realidade social e linguageira, que se manifesta através de comportamentos, discursos e ações. Assim, não há cultura fora de condições de produção, em que variam os interlocutores e os contextos histórico, político e econômico.

Uma vez que seja impossível definir um objeto, aconselham Abdallah-Pretceille e Porcher (idem) a aprender a utilizar suas variações, distorções e refrações culturais em movimento de compreensão e interpretação de acordo com dois eixos: o conhecimento do fato cultural e a articulação da culturalidade (a cultura em ação) e da comunicação, uma vez que a cultura se expressa em enunciados nos comportamentos sociais e discursivos. Sugerem a hermenêutica, para dar conta da intenção dos interlocutores, da relação interpessoal e do enunciado. Assim, o objeto da investigação não é conhecer o fato cultural em si, mas o verdadeiro sentido cultural que ele tem em relação a determinado grupo social.

"Em realidade, a antropologia hermenêutica se apóia também em uma pragmática de comunicação" (Abdallah-Pretceille e Porcher, 1996, p. 72). A partir de dados culturais, é importante ir além da formação de estereótipos culturais, de modo a interpretá-los. A pragmática representa, dessa forma, uma hipótese importante para a análise cultural e para a estruturação do processo. Para se comunicar, o indivíduo desenvolve uma competência pragmática, que Ihe permite, através da linguagem e da comunicação, apoderar-se da cultura.

Enfatiza-se que é através do comportamento linguageiro que o indivíduo 'diz' e 'se diz'. Prevalece o modelo orquestral, em que o sujeito, juntamente com o Outro, elabora os significados culturais de seu grupo em um movimento dialógico. A dimensão transacional é indissociável da produção de sentido, o qual passa necessariamente pela resposta do Outro e escapa da lógica normativa e atributiva.

O ensino de línguas abrange disciplinas propícias para a presença do elemento estrangeiro. $O$ que se tem observado até agora é uma didática de línguas mais baseada em lingüística aplicada em detrimento de uma concepção mais humanista no campo das ciências humanas.

Tem-se observado, no ensino de línguas, uma confusão de finalidades, objetivos e metodologias. A cultura, por sua vez, tem ocupado lugar secundário, em 
que mais se explica a comunicação do que se compreendem os contextos socioculturais. Para reverter esse quadro, é necessário apoiar-se em uma epistemologia de complexidade, e não na simplificação pura e simples dos atos comunicativos. A orientação pragmática pode constituir o ponto de equilíbrio entre o dogmatismo cultural e a evanescência do próprio objeto. "A pragmática pode, (...), ser introduzida nos estudos sobre as culturas e a comunicação intercultural (...); ela se apoiará em uma série de postulados suscetíveis de assegurar uma coerência teórica e funcional" (Abdallah-Pretceille e Porcher, 1990, p. 117).

Tais postulados constituem: a) trabalhar no nível dos objetivos, ou seja, no nível pragmático e não somente no semântico (para a língua) ou semiológico (para a cultura; b) entender que, ao se trocarem os signos, também se trocam os sentidos das mensagens, pois a cultura de um país se reproduz através de várias linguagens e conhecer as tradições culturais de um país auxilia a compreensão dos índices culturais; c) toda comunicação é dialógica, ou seja, é co-produzida, já que a alteridade antropológica é relacional e pensa-se em uma rede de intersubjetividade. Assim, não se pode riscar algo do contexto de uma interlocução sem riscar algo do Outro. A interação é, desse modo, primordial na produção cultural; d) a proposição de um método de análise e de compreensão, não da cultura como um ente, mas como um 'agir cultural'. Não será um estudo de estruturas fechadas, mas de fatos racionais e de estratégias, já que aponta a cultura da mestiçagem, em que o diferente é a norma. Aprender a observar, ver, compreender e avaliar as modalidades e os sentidos atribuídos aos elementos culturais na comunicação é o objetivo de uma competência intercultural.

Por outro lado, é o objeto que comanda a metodologia e não o contrário. Notese que a idéia de uma retórica cultural não se faz acompanhar necessariamente por um 'guia cultural'. Os procedimentos metodológicos para uma educação intercultural apresentam-se como a ênfase e a supervalorização do traço cultural, a redundância cultural, a presença/ausência de ambigüidades culturais e a implicitude. 


\section{CONCLUSÃO}

O ensino de línguas, especialmente das estrangeiras, não pode se furtar da abordagem intercultural, uma vez que se caracteriza por um alto grau de complexidade e de presença do diferente.

Com base em uma teoria pragmática da comunicação, a visão do 'eu' só se valoriza através da visão do 'Outro', em que a experiência da alteridade tem elevado valor e dá o sentido do universal-singular. O universal-singular é uma realidade (ou material ou simbólica) que existe em todos os lugares, e que cada sociedade interpreta à sua maneira, possibilitando uma pedagogia verdadeiramente comparatista.

Uma perspectiva intercultural do ensino apresenta, desse modo, duas características fundamentais: tudo que é humano é, por sua vez, diferente de mim e idêntico a mim. "Ela autoriza cada aluno a exprimir sua própria opinião sobre um fenômeno que o toca diretamente e que ele percebe de maneira singular, diferentemente da maneira singular de cada um dos outros" (Abdallah-Pretceille e Porcher, 1996, p. 142).

Nessa ótica, importante é o papel exercido pela literatura, que possibilita diferentes manifestações sobre o mesmo objeto, na medida em que este é universal e singular.

\section{BIBLIOGRAFIA}

ABDALLAH-PRETCEILLE, M. A.; PORCHER, L. Éducation et communication interculturelle. Paris: PUF, 1996.

BRASIL. Ministério da Educação e da Cultura. Parâmetros Curriculares Nacionais. 1997.

FLEURI, R. M. Multiculturalismo e interculturalismo nos processos educativos. Disponível em www.ced.ufsc.br/nucleos/mover. Acesso em 19 ago. 2003a.

Educação intercultural e complexidade: implicações epistemológicas e perspectivas pedagógicas da educação intercultural no Brasil. Disponível emwww.ced.ufsc.br/nucleos/mover. Acesso em 19 ago. 2003b.

MORIN, E. A cabeça bem feita: repensar a reforma, reformar o pensamento. Rio de Janeiro: Bertrand Brasil, 2000. 